\title{
Assessment of Changes in the Hemoglobin Level under the Influence of Comprehensive Spa Therapy Using Therapeutic Radon-Sulfur Waters and Its Correlation with Free Radical Reactions
}

\author{
Jadwiga Kuciel-Lewandowska $(\mathbb{D}$, Michał Kasperczak $(\mathbb{D}$, \\ and Małgorzata Paprocka-Borowicz $\mathbb{D}$
}

Department of Physiotherapy, Medical University of Wroclaw, Wroclaw, Poland

Correspondence should be addressed to Michał Kasperczak; mkasperczakmd@gmail.com

Received 22 January 2020; Revised 10 June 2020; Accepted 19 June 2020; Published 21 July 2020

Academic Editor: Manel Santafe

Copyright (c) 2020 Jadwiga Kuciel-Lewandowska et al. This is an open access article distributed under the Creative Commons Attribution License, which permits unrestricted use, distribution, and reproduction in any medium, provided the original work is properly cited.

\begin{abstract}
Introduction. Hemoglobin is a protein present in erythrocytes of higher organisms. Its main function is to transport oxygen from the lungs to tissues and carbon dioxide from tissues to the lungs. Hemoglobin contains $\mathrm{Fe}^{2+}$, catalyzes free radical reactions, and may initiate oxidation reactions by enzymatic and nonenzymatic degradation. The aim of the study was to evaluate the effect of balneophysiotherapy on the hemoglobin level in osteoarthritis patients and to try to assess the association of those metabolic changes with free radical reactions. Materials and Methods. The study was conducted in Przerzeczyn-Zdrój spa resort. It included patients receiving spa treatment over 21-day sessions. The studied group consisted of $n=122$ patients with joint and back pain due to osteoarthritis or disc herniation. Their age ranged between 32 and 67 years with a mean age of 53.5. Blood samples were collected before treatment and after 21 days at the spa. Standard tests were used. The results were statistically analyzed using the sign test and the Wilcoxon test. Results. In the study group, we observed a drop in the hemoglobin level following spa treatment. Before treatment, the mean hemoglobin level was $14.1549 \mathrm{~g} \%$, and after treatment, it was $14.0008 \mathrm{~g} \%$. Conclusions. (1) In the study, we concluded that balneophysiotherapy in osteoarthritis patients resulted in a decrease in the mean hemoglobin level. (2) The decrease in the mean hemoglobin level in osteoarthritis patients treated at the spa resort may indicate an association with free radical reactions. This trial was registered with NCT03405350.
\end{abstract}

\section{Introduction}

Hemoglobin is a protein present in erythrocytes of higher organisms. Its major function is to transport oxygen from the lungs to tissues and carbon dioxide from tissues to the lungs. It is composed of four polypeptide chains forming similar pairs (two alpha chains and two beta chains) as well as four heme prosthetic groups. Heme contains $\mathrm{Fe}^{2+}$ ions, which, in the presence of oxygen, are oxidized to $\mathrm{Fe}^{3+}$. In addition to the formation of a heme- $\mathrm{Fe}^{3+}$ complex, a superoxide radical $\mathrm{O}_{2}^{-}$is produced [1]. On the other hand, in the presence of other electron donors such as nitrates and aminophenols, a double-electron reduction of hemoglobinbound $\mathrm{O}_{2}$ can occur with the formation of $\mathrm{H}_{2} \mathrm{O}_{2}$. Both superoxide and hydrogen peroxide are classified as reactive oxygen species (ROS). Both compounds are by-products of many aerobic reactions. As a result of further reactions, the hydroxyl radical $\mathrm{OH}^{-}$is created, which is even more reactive. Initially, $\mathrm{Fe}^{2+}$ is oxidized in the presence of $\mathrm{H}_{2} \mathrm{O}_{2}$ (Fenton's reaction) followed by regeneration of the $\mathrm{Fe}^{2+}$ ion [2]. By combining both reactions, the so-called Haber's reaction is formed, which is catalyzed by $\mathrm{Fe}^{2+} / \mathrm{Fe}^{3+}$ ions:

$$
\mathrm{O}_{2^{-}}+\mathrm{H}_{2} \mathrm{O}_{2} \longrightarrow \mathrm{OH}+\mathrm{OH}^{-}+\mathrm{O}_{2} \text {. }
$$


The iron ions $\left(\mathrm{Fe}^{2+} / \mathrm{Fe}^{3+}\right)$ attached to proteins such as hemoglobin can catalyze the reactions shown above [1]. There are cell-protective mechanisms against ROS. They consist of enzymes catalyzing $\mathrm{O}_{2}{ }^{-}$and $\mathrm{H}_{2} \mathrm{O}_{2}$ breakdown. In healthy humans, around 3\% of hemoglobin can be oxidized to methemoglobin daily, which, in turn, cannot bind to oxygen. This reaction is the main source of superoxide [2,3]. Methemoglobin reductase catalyzes reduction of methemoglobin to hemoglobin and indirectly inhibits ROS formation. It also has been established that heme-containing proteins can, under certain circumstances, inhibit ROS synthesis, hydroxyl radical, in particular, in the presence of low-molecular-weight antioxidants, e.g., ascorbic acid [4]. Due to their structure and function, erythrocytes are sensitive to reactive oxygen species [5]. As can be observed, hemoglobin with $\mathrm{Fe}^{2+}$ contained in erythrocytes can catalyze free radical reactions, and as a result of enzymatic and nonenzymatic heme decomposition and loss of heme iron, the products can also initiate oxidation, which is essential for ROS generation. Hemoglobin is not only involved in autooxidation but can also be exposed to superoxides resulting from activation of other blood cells and oxidation of catecholamines and xenobiotics [6,7]. In the second stage, superoxide dysmutation leads to the formation of hydrogen peroxide, which takes part in heme degradation, followed by synthesis of soluble biliverdin further creating nonsoluble bilirubin and carbon monoxide in the presence of iron ions [8].

The oxygen free radicals, also called the reactive oxygen species (ROS), are atoms, molecules, or moieties with independent activity, which also contain one or more unpaired electrons in the valence shell. Those electrons determine the reactivity of the free radicals and initiate redox chain reactions, which is not favourable. The main source of free radicals in the body is the cellular respiration catalyzed by various enzymes. The free radicals are balanced by antioxidants, which are present in low concentration but significantly inhibit oxidation [9]. ROS includes singleton oxygen ${ }^{1} \mathrm{O}_{2}$, superoxide $\mathrm{O}_{2}^{-}$, hydrogen peroxide $\mathrm{H}_{2} \mathrm{O}_{2}$, and hydroxyl radical $\mathrm{OH}$ [10]. In health, the free radical level is strictly controlled keeping balance between formation and degradation of reactive oxygen species. The imbalance leads to oxidative stress. The oxidative stress is when the antioxidant drops or when the ROS production is increased for various reasons [11]. As long as there is a balance between ROS formation and elimination, they are harmless for the body. The imbalance leads to manifestation of the toxic effect of ROS, including inflammatory disorders of the muskuloskeletal system. It is followed by a cascade of enzymatic reactions leading to hialuronic acid depolymerization, loss of tissue elasticity, proteoglycan and collagen degradation, protein oxidation and inhibition of chondrocyte proliferation [12]. Free radicals also take part in pathogenesis of other disorders such as atherosclerosis, neurogenerative diseases including Alzheimer's or Parkinson's disease, inflammation, allergy, cancer, diabetes, and macular degeneration [13, 14]. The human body has a couple of mechanisms regulating (limiting) production of free radicals. The antioxidation system consists of antioxidants. The antioxidation system includes:

(1) Endogenous antioxidants produced by the body:

(i) Enzymatic: superoxide dysmutase (SOD), glutathione peroxidase (GSH-Px), and catalase

(ii) Nonenzymatic: linolenic acid, polyamides, albumin, bilirubin, glutathione, uric acid, ceruloplasmin, transferrin, and coenzyme Q10, with different targets

(2) Exogenous antioxidants consumed with food: vitamins C, A, and E, carotenoids, xantophiles, and polyphenols. They indirectly take part in the free radical reaction affecting cellular signalling pathways, activity of enzymes and genes engaged in apoptosis, and DNA repair [15].

The aim of the study was to evaluate the effect of balneophysiotherapy on the hemoglobin level in osteoarthritis patients and to try to determine whether this effect is associated with free radical reactions.

\section{Materials and Methods}

The study was conducted at the spa resort in PrzerzeczynZdroj on patients receiving spa treatment during 21-day sessions. The patients' blood samples were collected from the ulnar vein using a vacuum tube before treatment and after 18 days. The blood samples were centrifuged, and the plasma was kept at $+6^{\circ} \mathrm{C}$ before testing. The patient group consisted of $n=122$ patients with peripheral and spinal osteoarthritis, including 91 females and 31 males aged 32 to 67, with the mean age of 53.5. The main inclusion criterion was the presence of peripheral and/or spinal osteoarthritis and no contraindications for complex spa treatment. The patients above 80 years were excluded. Most patients received normal or light diet, mainly containing cooked dishes with low fat content. Both diets had normal caloric intake. The patients were offered a series of 10 sessions of each type of intervention depending on their needs and diseases. The treatment options included sulfide-radon baths, peloid compresses, therapeutic exercises in groups and individually, biostimulation with lasers, and interferential current. The complex spa treatment included the following:

(i) Sulfide-radon baths including whole body or only upper and/or lower extremities at the temperature of $37-38^{\circ} \mathrm{C}$ for $20 \mathrm{~min}$

(ii) Partial peloid compresses, time $20 \mathrm{~min}$, and temp. $40-42^{\circ} \mathrm{C}$

(iii) Therapeutic exercises in the swimming pool with neutral water

(iv) Individual exercises with equipment or group exercises selected for each patient depending on his or her fitness; mean duration 30-45 min

(v) Field therapy: walking and outdoor exercises

(vi) Dry massage of the cervical (CC), thoracic (TH), or lumbosacral (LS) spine; 
(vii) Laser therapy: parameters: pulse or continuous mode, wavelength $808 \mathrm{~nm}$, power $12.0 \mathrm{~J}, 400 \mathrm{mV}$, and duration $30 \mathrm{~s}$

(viii) Low-frequency magnetic field: duration $20 \mathrm{~min}$, square impulse, induction $5 \mathrm{mT}$, and frequency $20-50 \mathrm{~Hz}$

(ix) Ultrasound therapy: parameters: probe $800 \mathrm{kHz} / 6 \mathrm{~cm}^{2}$, impulse waves: $2 \mathrm{~ms}$ impulse, $9 \mathrm{~ms}$ break, at the dose of $0.5-0.6 \mathrm{~W} / \mathrm{cm}^{2}$ over $6 \mathrm{~min}$

(x) Cryotherapy: ventilation, duration 2-3 min and temp. between $-80^{\circ} \mathrm{C}$ and $-110^{\circ} \mathrm{C}$

(xi) Electrotherapy: Berndard's didynamic current, parameters: DF1 CP4 LP4, Nemec's interferential current (frequency $0-100 \mathrm{~Hz}$ ), transcutaneous electrical nerve stimulation (TENS): square wave, impulse $0.2 \mathrm{~ms}$, frequency $40 \mathrm{~Hz}$, and regulated current $0-100 \mathrm{~mA}$

(xii) Phototherapy: Sollux lamp with a blue filter, distance $30-40 \mathrm{~cm}$; duration $15 \mathrm{~min}$ and Bioptron lamp-distance $10 \mathrm{~cm}$; duration 5-10 min

Particularly important was, unique in Europe, the healing water at Przerzeczyn-Zdroj spa. Table 1 shows the physical and chemical properties of the water.

The chemical composition characteristic for Przerzeczyna-Zdroj water was within the ranges established over years of observation.

The study design included a control group, which consisted of 14 individuals selected from the resort staff, including 10 females and 4 males aged 24 to 58 with the mean age of 41.7. Healthy nonsmokers and nondrinkers were included in the control group. They were advised to carry on their usual lifestyle and were asked not to use any of the treatment options available at the resort.

The study was approved by the Bioethics Committee of Wroclaw Medical University, Resolution No. KB-401/2008, as well as by the Head of Uzdrowisko Przerzeczyn Sp. z o.o., and each patient gave his or her informed consent. The documents are in the author's possession.

The results were statistically analyzed using the STATISTICA 9.1 and Microsoft Excel 2007 software. For statistically significant differences, the detailed information was obtained by descriptive statistics, comparing medians, means, and quartiles. The differences before and after treatment were evaluated in each group using the Wilcoxon test and the sign test. The significance level was set at $\alpha=0.05$.

\section{Results}

In the studied group, we observed a drop in the hemoglobin level. The mean hemoglobin level before treatment (HGB1) was $14.1549 \mathrm{~g} \%$ and $14.0008 \mathrm{~g} \%$ after treatment (HGB2) Figure 1.

The decrease in the hemoglobin level was statistically significant $p=0.005$ in both tests.

The descriptive statistics are shown in Table 2.
In the control group, the mean $\mathrm{Hfb}$ level decreased from $13.9210 \mathrm{~g} \%$ before treatment (HGB1) to $13.6210 \mathrm{~g} \%$ after treatment (HGB2). Figure 2.

For the control group, we used the same tests to compare the results. In Wilcoxon test, $p=0.058$, while in the sign test, $p=0.092$, which means that the differences are not statistically significant. The median and mean also indicate a negligible drop in the Hgb level after the observation in the control group. The descriptive statistics for the control group are shown in Table 3.

\section{Discussion}

In our study, we observed a statistically significant drop in the hemoglobin level after treatment in patients receiving spa treatment. We searched scientific databases and found studies evaluating the effect of balneotherapy on the hemoglobin level. Different outcomes have been reported, usually an increase in the hemoglobin level. Durda et al., in their study on water rich in sulfur and hydrogen sulfide, showed an increase in the hemoglobin level. The authors believe that the baths stimulate redox reactions, which is indicated by an increase in the hemoglobin level and erythrocyte count [16]. Misztela et al. also observed a rise in the hemoglobin level in patients with rheumatoid arthritis receiving artificial sulfur and hydrogen sulfide baths [17]. Frih et al., in their study on dialysis patients receiving kinesiotherapy, observed no change in the hemoglobin level [18]. The study by $\mathrm{L} \mathrm{Xu}$ et al. showed that balneotherapy resulted in an increase in the erythrocyte count, hemoglobin level, and hematocrit [19]. Jokić et al. showed that treatment with sulfur and peloid baths in patients with hip and knee osteoarthritis led to a significant reduction in plasma lipid peroxidation and changed plasma activity of superoxide dysmutase and catalase. A significant increase in the hemoglobin level was observed, which was assumed to be a result of inhibited production of excess free radicals [20]. The study by Zinchuk et al. showed that dry sauna causes a drop in the hemoglobin level. A single visit to the sauna causes oxidative stress, and its symptoms are less pronounced after repeated exposure to heat [21]. In addition to a decrease in the hemoglobin level, our study showed an increase in the total antioxidative level and changes in specific components of the endogeneous antioxidation system, i.e., decease in the albumin and bilirubin level, as well as an increase in uric acid concentration, suggestive of free radical reactions $[22,23]$.

The activation of free radical reactions is the body's response to the balneotherapeutic stimulus. Later, the accumulation of balneotherapeutic stimuli causes metabolic shift and activation of defense mechanisms. The antioxidant production increases. The end result is an increased total antioxidant level, activation of adaptive processes, and regeneration dependent on largely unexplained functional and structural changes associated with the autonomous system activation. This mechanism can be a foundation for positive systemic changes leading to improved health after spa treatment [24]. 
TABLE 1: The results of physical and chemical testing on 24.04.2008 of the healing water at the spring and the natural therapy resort (NTR), our own source.

\begin{tabular}{|c|c|c|c|c|c|c|c|}
\hline \multirow{2}{*}{ No } & \multirow{2}{*}{ Sample location } & \multirow{2}{*}{ Water temp. in $\left({ }^{\circ} \mathrm{C}\right)$} & \multirow{2}{*}{$\mathrm{pH}$} & \multicolumn{4}{|c|}{ The content of the ingredient in $1 \mathrm{dm}^{3}$ of water } \\
\hline & & & & $\mathrm{H}_{2} \mathrm{~S} \mathrm{Mg}$ & $\mathrm{HCO}_{3} \mathrm{Mg}$ & Rn NCi & $\mathrm{Rn} \mathrm{Bq}$ \\
\hline 1. & Hole no II & 12.0 & 7.62 & 1.96 & 263.2 & 2.21 & 81.8 \\
\hline 2. & Hole no IX & 12.0 & 7.72 & 1.70 & 289.6 & 1.71 & 63.3 \\
\hline 3. & Tub MSP & 16.0 & 7.65 & 1.87 & 277.9 & 2.20 & 81.4 \\
\hline
\end{tabular}

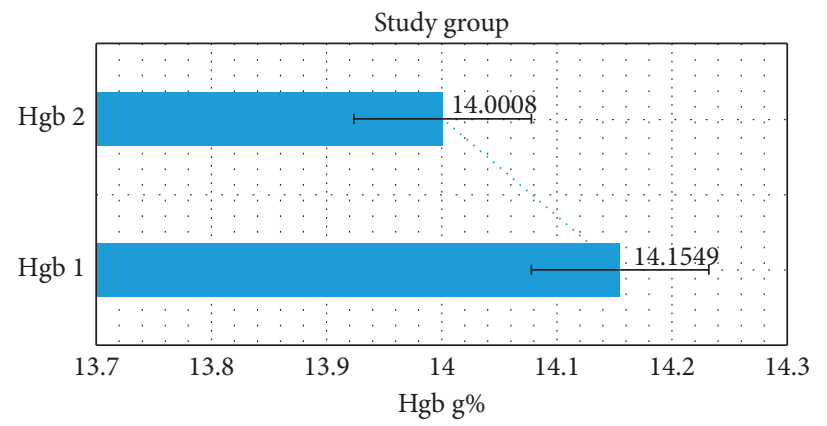

FIGURE 1: The change in the mean Hgb level before and after treatment in the studied group.

TABLE 2: Descriptive statistics: study group.

\begin{tabular}{lccccccc}
\hline HGB & $N$ & Mean & Standard deviation & Minimum & Maximum & \multicolumn{2}{c}{$\begin{array}{c}\text { Percentiles } \\
\text { 25. }\end{array}$} \\
\hline HGB1 & 122 & 14,1549 & 1,2926 & 9,9000 & 17,4000 & 13,2000 & 14,1000 \\
HGB2 & 122 & 14,0008 & 1,3095 & 9,8000 & 17,4000 & 13,1000 & 14,0000 \\
\hline
\end{tabular}

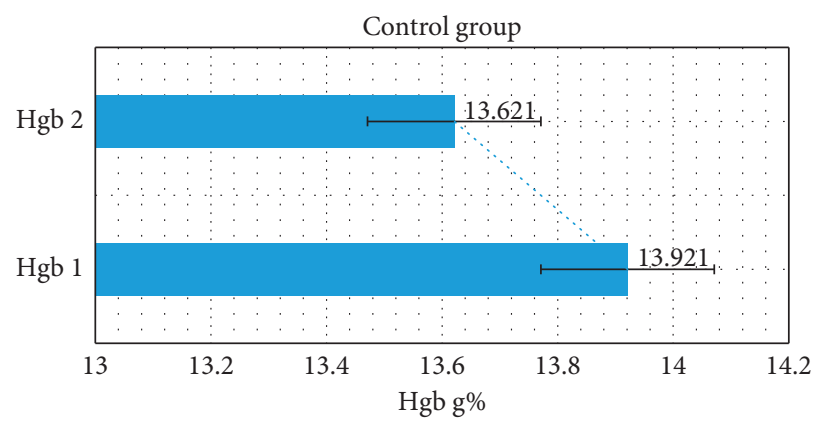

FIgURE 2: The change in the mean Hgb value before and after the observation period in the control group.

TABle 3: Descriptive statistics: control group.

\begin{tabular}{|c|c|c|c|c|c|c|c|c|}
\hline \multirow{2}{*}{ HGB } & \multirow{2}{*}{$N$} & \multirow{2}{*}{ Mean } & \multirow{2}{*}{ Standard deviation } & \multirow{2}{*}{ Minimum } & \multirow{2}{*}{ Maximum } & \multicolumn{3}{|c|}{ Percentiles } \\
\hline & & & & & & 25. & 50. (median) & 75. \\
\hline HGB1 & 14 & 13,921 & 1,2071 & 12,1000 & 15,9000 & 13,1500 & 13,4000 & 15,0500 \\
\hline HGB2 & 14 & 13,621 & 0,9267 & 12,0000 & 15,1000 & 12,9700 & 13,5000 & 14,5000 \\
\hline
\end{tabular}

There have been various and contradictory outcomes reported, depending on specific comorbidities and types of intervention. As far as healing water is concerned, the metabolic response depends on the chemical content and pharmacodynamic properties of the water. A significant effect (increase in hemoglobin) was observed in response to sulfur-rich water having particular metabolic activity. So, how to explain the decrease in the hemoglobin level in patients at Przerzeczyna-Zdroj? Generally speaking, a lower hemoglobin level is not a desirable outcome. It can be presumed that radon is a strong stimulus (stressor), activating a free radical reaction in the body. The main activating element responsible for metabolic changes is thought to be low-dose alpha radiation. The main mechanism might be radiation hormesis activating hemoglobin. Hemoglobin is mainly responsible for oxygen transport, but it also catalyzes free radical reactions and inhibits ROS formation [25]. 
Contradictory results by other authors indicate that further multidisciplinary studies evaluating the full blood count, heme degradation products, and iron metabolism are necessary. Because we were unable to clearly determine factors responsible for different results, randomized clinical trials on large groups of patients receiving isolated forms of treatment are necessary. Many factors affect the hemoglobin level. The changes in the hemoglobin level cannot always be easily interpreted. Evaluation of hemoglobin solely as a part of free radical reaction is not enough for the assessment of the antioxidation system; however, both are closely related. The observed changes signal metabolic shifts in response to balneotherapeutic stimuli.

\section{Conclusions}

(1) In this study, we concluded that balneophysiotherapy in osteoarthritis patients resulted in a decrease in the mean hemoglobin level

(2) The decrease in the mean hemoglobin level in osteoarthritis patients treated at the spa resort may indicate a correlation with free radical reactions

\section{Data Availability}

All data are contained and described within the manuscript. The datasets used and/or analyzed during the current study available from the corresponding author on reasonable request. The number of clinical trial is NCT03405350. All information about this study is available under this number.

\section{Disclosure}

The study was carried out as part of the statutory task SUB.E060.19.001 The presentation "Impact of balneophysiotherapy on changes in hemoglobin levels in patients with osteoarthritis of the musculoskeletal system and dependency of the changes from free radical processes" was given at the 26th Congress of the Polish Physiological Society, Szczecin (Poland), September 18-20, 2014. The authors presented with preliminary results of our study, which have, now, been properly developed and described in the attached article.

\section{Conflicts of Interest}

The authors report no conflicts of interest in this work.

\section{References}

[1] J. M. Rifkind, S. Ramasamy, P. T. Manoharan, E. Nagababu, and J. G. Mohanty, "Redox reactions of hemoglobin," Antioxidants \& Redox Signaling, vol. 6, no. 3, pp. 657-666, 2004.

[2] V. Chobot and F. Hadacek, "Iron and its complexation by phenolic cellular metabolites," Plant Signaling \& Behavior, vol. 5, no. 1, pp. 4-8, 2010.

[3] S. W. Ryter, J. Alam, and A. M. K. Choi, "Heme oxygenase-1/ carbon monoxide: from basic science to therapeutic applications," Physiological Reviews, vol. 86, no. 2, pp. 583-650, 2006.

[4] C. H. Foyer and G. Noctor, "Redox homeostasis and antioxidant signaling: a metabolic interface between stress perception and physiological responses," The Plant Cell, vol. 17, no. 7, pp. 1866-1875, 2005.

[5] J. P. Hale, C. P. Winlove, and P. G. Petrov, "Effect of hydroperoxides on red blood cell membrane mechanical properties," Biophysical Journal, vol. 101, no. 8, pp. 1921-1929, 2011.

[6] J. Bylund, K. L. Brown, C. Movitz, C. Dahlgren, and A. Karlsson, "Intracellular generation of superoxide by the phagocyte NADPH oxidase: how, where, and what for?," Free Radical Biology and Medicine, vol. 49, no. 12, pp. 1834-1845, 2010.

[7] O. Terland, B. Almås, T. Flatmark, K. K. Andersson, and M. Sørlie, "One-electron oxidation of catecholamines generates free radicals with an in vitro toxicity correlating with their lifetime," Free Radical Biology and Medicine, vol. 41, no. 8, pp. 1266-1271, 2006.

[8] U. Florczyk, A. A. Jozkowicz, and J. J. Dulak, "Biliverdin reductase: new features of an old enzyme and its potential therapeutic significance," Pharmacological Reports, vol. 60, pp. 38-48, 2008.

[9] A. Wiktorowska-Owczarek and J. Nowak, "Pathogenesis and prophylaxis of AMD: focus on oxidative stress and antioxidants," Postępy Higieny i Medycyny Doświadczalnej, vol. 64, pp. 333-343, 2010.

[10] N. R. Perron and J. L. Brumaghim, "A review of the antioxidant mechanisms of polyphenol compounds related to iron binding," Cell Biochemistry and Biophysics, vol. 53, no. 2, pp. 75-100, 2009.

[11] A. Roessner, D. Kuester, P. Malfertheiner, and R. SchneiderStock, "Oxidative stress in ulcerative colitis-associated carcinogenesis," Pathology-Research and Practice, vol. 204, no. 7, pp. 511-524, 2008.

[12] D. Li, W. Wang, and G. Xie, "Reactive oxygen species: the 2edged sword of osteoarthritis," The American Journal of the Medical Sciences, vol. 344, no. 6, pp. 486-490, 2012.

[13] M. Makowski, T. Grzela, and J. Niderla, "i wsp. Inhibition in cyclooxygenase-2indirectly potentiates antitumor effects of photodynamic therapy in mice," Clinical Cancer Research, vol. 9, pp. 5417-5422, 2003.

[14] N. Ryszawa, A. Kawczyńska-Drożdż, J. Pryjma et al., "Effects of novel plant antioxidants on platelet superoxide production and aggregation in arteriosclerosis," Journal of Physiology and Pharmacology, vol. 57, pp. 611-626, 2006.

[15] K. Rahman, "Studies on free radicals, antioxidants, and cofactors," Clinical Interventions in Aging, vol. 2, pp. 563-567, 2007.

[16] A. Durda, B. Solecki, M. Maj, P. Leśniewski, and W. Kuliński, "The influence of saline sulfide-sulphuretted hydrogen waters on the efficiency of the glycolytic path in erythrocytes of the suffering from degenerative spine disease," Acta Balneologica, vol. 1, no. 4, pp. 4-14, 2011.

[17] A. Misztela, W. Kuliński, and P. Leśniewski, "Evaluation of selected indicators of rheumatoid arthritis activity after artificial sulfur-hydrogen sulfide bath," Baln Pol, vol. 3-4, pp. 21-25, 2001.

[18] B. Frih, H. Jaafar, W. Mkacher, Z. Ben Salah, M. Hammami, and A. Frih, "The effect of interdialytic combined resistance and aerobic exercise training on health related outcomes in chronic hemodialysis patients: the Tunisian randomized controlled study," Frontiers in Physiology, vol. 8, p. 288, 2017.

[19] L. Xu, L. Wu, T. Liu et al., "Effect of a 21-day balneotherapy program on blood cell counts, ponogen levels, and blood biochemical indexes in servicemen in sub-health condition," Journal of Physical Therapy Science, vol. 29, no. 9, pp. 15731577, 2017. 
[20] A. Jokic, N. Sremcevic, T. Z. Pekmezovic, V. Davidovic, and V. Davidović, "Oxidative stress, hemoglobin content, superoxide dismutase and catalase activity influenced by sulphur baths and mud packs in patients with osteoarthritis," Vojnosanitetski Pregled, vol. 67, no. 7, pp. 573-578, 2010.

[21] V. V. Zinchuk and D. D. Zhad'ko, "Sauna effect on blood oxygen transport function and proxidant/antioxidant balance in youths," Fiziol Cheloveka, vol. 38, no. 5, pp. 112-119, 2012.

[22] J. Kuciel-Lewandowska and M. Paprocka-Borowicz, "The impact of integrated antioxidant system in patients with osteoarthritis musculoskeletal and non-pharmacological therapies," Acta Balneologica, vol. 59, no. 4, pp. 304-309, 2017.

[23] J. Kuciel-Lewandowska, M. Kasperczak, B. Bogut et al., "The impact of health resort treatment on the nonenzymatic endogenous antioxidant system," Oxidative Medicine and Cellular Longevity, vol. 2020, Article ID 8423105, 9 pages, 2020.

[24] P. Kalmus and L. Szynkowska, "Obserwations of the adaptive reactions in patients with inflammatory rheumatic diseases during health resort therapy," Acta Balneologica, vol. 57, no. 140, pp. 97-105, 2015.

[25] J. M. Rifkind, S. Ramasamy, P. T. Manoharan, E. Nagababu, and J. G. Mohanty, "Redox reactions of hemoglobin," Antioxidants \& Redox Signaling, vol. 6, no. 3, pp. 657-666. 